\title{
Aplicaciones de materiales aloplásticos en rinoplastía
}

\author{
Applications of aloplastic materials in rhinoplasty \\ Alfredo Abarca A ${ }^{1}$, Alfredo Naser $\mathbf{G}^{\mathbf{1}}$, Javiera Pardo J².
}

\begin{abstract}
RESUMEN
Esta revisión aborda específicamente el uso de materiales aloplásticos en rinoplastía. Es importante destacar que los injertos autólogos siguen siendo los materiales preferidos en rinoplastía, debido a su alta biocompatibilidad y bajo riesgo de infección y extrusión. Sin embargo, las dificultades relacionadas al sitio donante, disponibilidad del injerto y reabsorción de éste han motivado el desarrollo y uso de implantes aloplásticos.

Después de leer este artículo, el lector debe ser capaz de identificar los usos apropiados de implantes aloplásticos en reconstrucción y reconocer las ventajas y desventajas de cada uno de estos biomateriales.
\end{abstract}

Palabras clave: Injertos, aloplásticos, rinoplastía, implantes.

\begin{abstract}
This review specifically addresses the use of alloplasts materials in rhinoplasty. It is important to stress that autologous grafts remain the preferred material for use in rhinoplasty, owing to their high biocompatibility and low risk of infection and extrusion. However, concerns of donor-site morbidity, graft availability, and graft resorption have motivated the development and use of alloplasts implants. After reading this article, the reader should be able to identify the appropriate uses of various implants in reconstruction and recognize the advantages and disadvantages of each of these biomaterials.
\end{abstract}

Key words: Grafts, alloplasts, rhinoplasty, implants.

Médico. Servicio de Otorrinolaringología, Hospital Clínico Universidad de Chile

2 Médico Cirujano. Tesista de Magíster en Ciencias Biomédicas, mención Neurociencias, Universidad de Chile. 


\section{INTRODUCCIÓN}

La rinoplastía ha cambiado su enfoque en los últimos 10 a 15 años desde una rinoplastía agresiva reductiva a uno con mayor énfasis en el aumento nasal. Consecuencia de esto ha surgido la necesidad de contar en la plástica nasal con materiales de soporte, relleno y camuflaje. Existen variados tipos de injertos y aloplásticos disponibles para uso quirúrgico en la actualidad y su elección depende de múltiples factores ${ }^{1-3}$.

Los injertos pueden ser divididos en dos grandes categorías, los autoinjertos, los cuales son derivados del propio paciente e incluyen cartílago, hueso, fascia y dermis; y los homoinjertos, los que son derivados de tejidos donados por miembros de la misma especie, e incluyen cartílago irradiado y dermis acelular. Los injertos autólogos tienen una alta biocompatibilidad y un bajo riesgo de infección y de extrusión comparado con los homoinjertos y aloplásticos. Siguen siendo, por lejos, los materiales preferidos en rinoplastía por la gran mayoría de los cirujanos ${ }^{4,5}$. Sin embargo sus ventajas deben ser comparadas con la consecuente morbilidad del sitio donante, disponibilidad del injerto y reabsorción de éste. Por otra parte, en narices malformadas $y$, principalmente, en rinoplastías secundarias, es frecuente encontrarse con escasez de injertos necesarios para una adecuada reconstrucción ${ }^{1-5}$.

Los homoinjertos son materiales obtenidos a partir de miembros de la misma especie, incluyen el cartílago irradiado y la dermis acelular cadavérica. El cartílago irradiado es obtenido de costillas de donantes cadáveres, a quienes se realiza un tamizaje para $\mathrm{VIH}$, hepatitis $\mathrm{B}$, enfermedades venéreas y tuberculosis. Siendo posteriormente irradiados con rayos gama a dosis de 30.000 a 60.000 Gy. Debido a la ausencia de celularidad, son no inmunogénicos y bien tolerados por el huésped. Sin embargo, una de sus principales desventajas es la reabsorción, cercana al 10\%. Las tasas de infección, desplazamiento del injerto y extrusión son aceptables, en general menor al 5\%. La dermis acelular se obtiene de donante cadáver, siendo luego congelada en seco. Carece de antígenos del complejo mayor de histocompatibilidad tipo I y II, por lo que es altamente biocompatible. Se usa para la corrección y camuflaje de irregularidades del dorso nasal' ${ }^{1}$.
Los materiales aloplásticos son polímeros sintéticos biocompatibles desarrollados para ser usados en cirugía. En los últimos años se ha introducido su uso en rinoplastía, es por esto que consideramos que sus propiedades y aplicaciones deben ser conocidas por los profesionales que se relacionan con esta cirugía. El objetivo de esta revisión es mostrar los diferentes tipos de materiales aloplásticos utilizados actualmente en rinoplastía, analizando sus usos específicos, propiedades, ventajas y desventajas.

\section{PROPIEDADES Y APLICACIONES DE LOS MATERIALES ALOPLÁSTICOS EN RINOPLASTÍA}

Los materiales aloplásticos han sido utilizados en procedimientos quirúrgicos desde 1930. Tienen la ventaja de acortar los tiempos de reconstrucción, encontrarse en cantidades ilimitadas, con propiedades específicamente diseñadas. Dentro de sus desventajas se encuentra el riesgo de incompatibilidad, incluso años después de la cirugía, riesgo de infección, migración, extrusión y la posibilidad de cambios en sus propiedades físicas luego de su colocación. No existen estudios en humanos que muestren malignización inducida como resultado de implantes a la fecha. La utilización de estos biomateriales continúa siendo materia de debate y controversia, habiéndose introducido en plástica nasal recientemente, siendo muchos de éstos popularizados por la industria cosmética ${ }^{1-3}$.

A modo didáctico, podemos clasificar a estos materiales en aloplásticos implantables e inyectables. Los implantables son aquellos que requieren un acceso quirúrgico para su colocación, mientras los otros se inyectan vía transdérmica (Figura 1).

\section{Materiales implantables}

a) Silicona (Silastic ${ }^{\circledR}$ )

La silicona constituye un material sólido elástico, no poroso, no degradable, fácilmente moldeable y autoclavable. Ha sido usado en tejidos blandos por ser poco reactivo, creando una cápsula fibrosa. Sin embargo, al ser un material bioinerte, de estructura no porosa, se incrementa el riesgo de infección y eventual extrusión como resultado del espacio muerto entre el injerto y los tejidos del huésped ${ }^{2,3,6}$. 


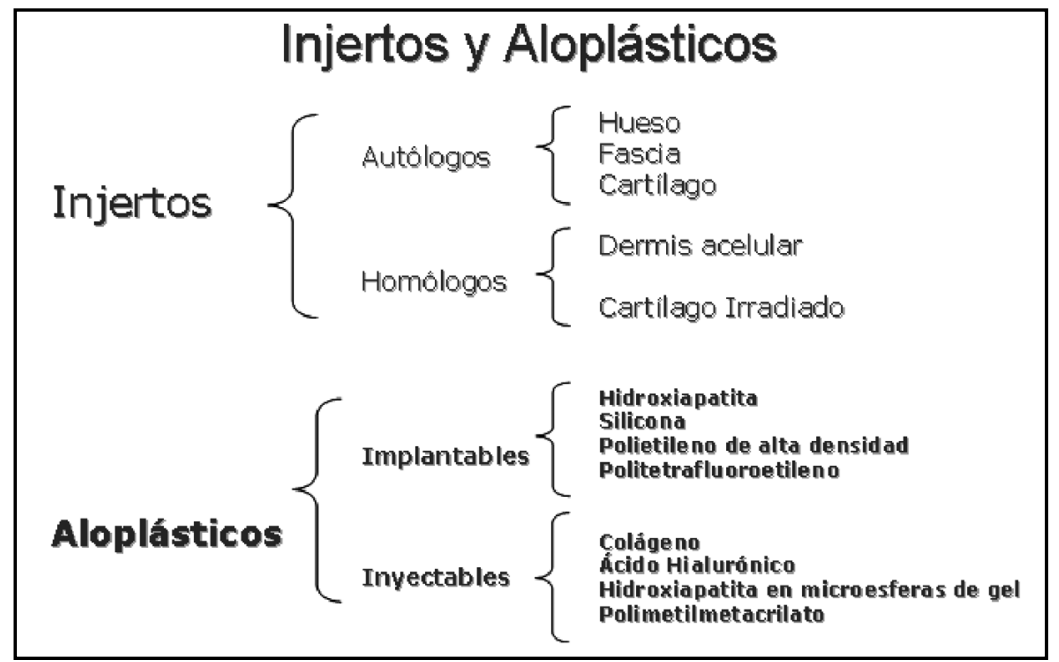

Figura 1. Tipos de injertos y aloplásticos.

En rinoplastía se ha usado en dorso y punta, principalmente como material de aumento nasal. La tasa de complicaciones reportada va desde $5,6 \%$ a $16 \%$, siendo las más comunes: infección, desplazamiento, extrusión y visibilidad excesiva. Motivo por lo que ha perdido popularidad en occidente. Actualmente se usa extensamente en cirugía de aumento nasal en países asiáticos, reportando baja tasa de complicaciones. Haciendo énfasis en la técnica, destacando aspectos como la tensión sobre el implante y la colocación subperióstica del implante ${ }^{7,8}$.
En resumen, el uso de silicona es aceptado en casos seleccionados de cirugías de aumento. Principalmente en pacientes con cartílago septal inadecuado que se nieguen al uso de cartílago costal o de concha (Figura 2).

b) Polietileno de alta densidad (Medpore ${ }^{\circledR}$ )

El polietileno de alta densidad es un plástico microporoso, desarrollado en la década de 1970. Tiene la ventaja de ser moldeable con calor, tallable, suturable y biocompatible. Las piezas pueden ser suturadas 0 atornilladas en conjunto cuando sea necesario. Su dureza es similar al hueso esponjoso a temperatura ambiente, pero ha demostrado exce-

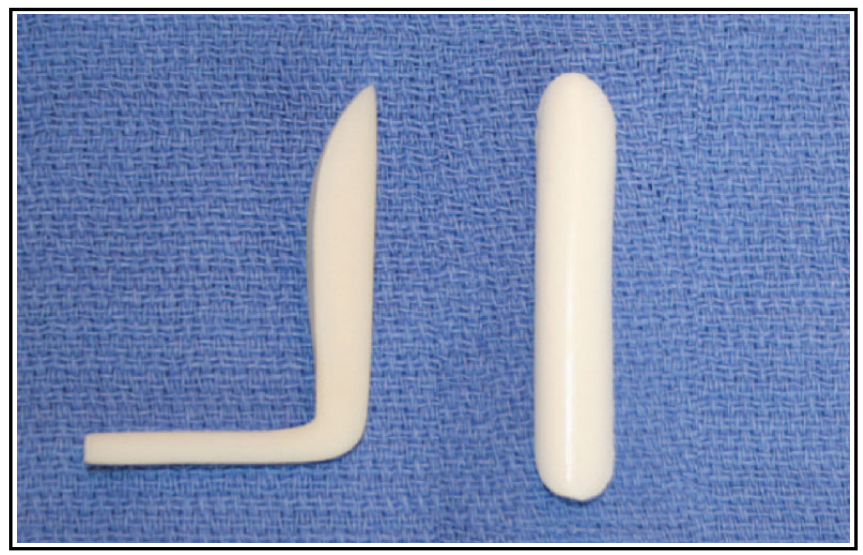

Figura 2. Implante de silicona. Tomado de Sajjadian A, Naghshineh N, Rubinstein R. Current status of grafts and implants in rhinoplasty: Part II. Homologous grafts and allogenic implants. Plast Reconstr Surg 2010; 125(3): 99e-109e. 
lentes habilidades termoplásticas y puede ser moldeado fácilmente después de ser sumergido en solución salina a altas temperaturas $\left(80^{\circ} \mathrm{C}-100^{\circ} \mathrm{C}\right)$ por pocos minutos ${ }^{2,3}$.

Al poseer poros de 200 um se integra fácilmente al tejido conectivo circundante, logrando el paso de vascularización. Esto permite un gran crecimiento de tejido, con excelente fijación del implante, muy baja reabsorción y bajas tasas de infección y exposición. Tiene una óptima fijación a través del tejido en crecimiento hacia el hueso subyacente cuando es implantado en el bolsillo subperióstico?.

Sus propiedades han incrementado no sólo el uso en rinoplastía, sino también en cirugías reconstructivas del tercio medio de la cara y pabellón auricular.

En naríz se emplea como soporte septal, spreader graft y reemplazo de cartílagos alares. Se han reportado excelentes resultados en el manejo de laterorrinias, utilizados como tutores septales ${ }^{9,10}$. En contraste, en sitios expuestos da una apariencia poco natural por su dureza. Además, cuando es implantado en áreas móviles y de tensión produce una respuesta inflamatoria crónica. Como otros materiales porosos, el crecimiento extenso de tejido puede hacer dificultosa la remoción del implante, por lo que requiere resecar el tejido que rodea al implante $^{9-11}$ (Figura 3).

c) Politetrafluoroetileno (Gore-Tex ${ }^{\circledR}$ )

El politetrafluoroetileno es un polímero hidrofóbico compuesto por moléculas de carbón y fluorina con poros de $30 \mu \mathrm{m}$, los que limitan el crecimiento del tejido conectivo, además dis-

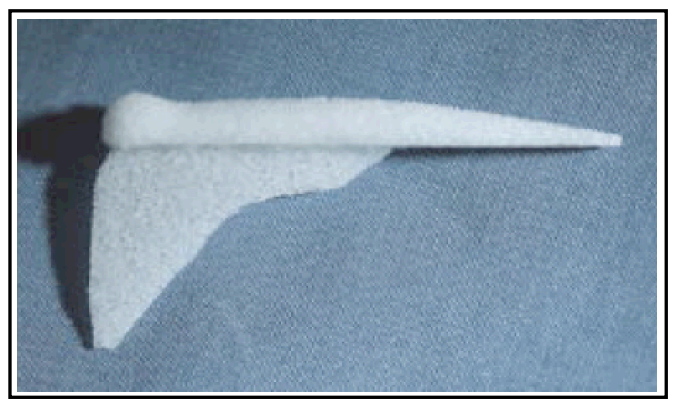

Figura 3. Implante de polietileno de alta densidad. Tomado de Berghaus A, Stelter K. Alloplastic materials in rhinoplasty. Curr Opin Otolaryngol Head Neck Surg 2006; 14(4): 270-7. minuye la adherencia de bacterias. Es de fácil remoción en caso necesario ${ }^{2,3}$.

Dado su aspecto natural y suavidad al tacto, este implante es comúnmente usado en dorsos sobrerresecados, ya sea contorneados o acodados, cubriendo un gran defecto 0 disfrazando irregularidades menores. Es una mala alternativa cuando se requiere soporte estructural, como en válvula nasal, septo y reconstrucción columelar. Ha demostrado excelente biocompatibilidad en diversos órganos, describiéndose menos de $3 \%$ de complicaciones ${ }^{12,13}$. Diversos estudios muestran una tasa de infecciones relacionadas al uso de Gore-Tex en rinoplastía consistentemente baja, con una tasa acumulativa de 2,6\%2,3,12,13.

\section{Materiales inyectables}

Son materiales de relleno que permiten corregir o camuflar deficiencias menores de volumen nasal, no proveyendo soporte estructural. Se inyectan vía transdérmica en forma retrógrada mediante microcánulas (Figura 4).

a) Colágeno (CosmoDerm ${ }^{\circledR}$ )

Formado principalmente por colágeno tipo I, se encuentra disponible de origen bovino y humano. Debido a que presenta reabsorción precoz del $20 \%$ a $30 \%$ de lo inyectado, es necesaria la sobrecorrección del defecto. Presenta reabsorción casi completa al noveno mes, requiriendo sucesivas aplicaciones. El paciente presenta frecuentemente una reacción inflamatoria local transitoria durante las 72 horas posteriores a la inyección.

El colágeno de origen bovino es el más ampliamente usado en la actualidad, requiere un test de alergia previo a su uso. En los últimos años se ha introducido el uso de colágeno humano, disminuyendo la tasa de alergias ${ }^{2,3}$.

b) Ácido hialurónico (Restylane ${ }^{\circledR}$ )

Polisacárido, biocompatible, presente naturalmente en tejidos conjuntivos, de origen humano, animal y bacteriano. Muy similar en sus propiedades al colágeno, aunque de mayor duración, presentando reabsorción casi completa al $12^{\circ}$ mes $^{2,3}$.

c) Hidroxiapatita (Radiesse ${ }^{\circledR}$ )

La hidroxiapatita es un componente mineral de la matriz ósea. Su uso permite osteoconducción y osteointegración. Tiene la ventaja de ser 


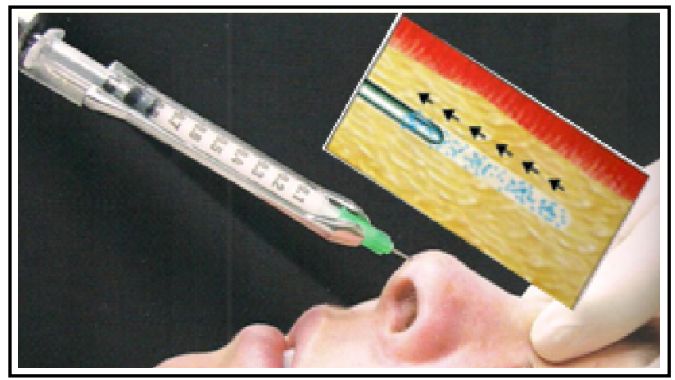

Figura 4. Inyección retrógrada con microcánula. Tomado de Nácul A. Bioplastía Nasal. En: Nácul A, Bioplastía: la plástica interactiva. Sao Paulo: Amolca, 2009; 85-110.

biocompatible y su efecto es perdurable en el tiempo. Se inyecta como microesferas suspendidas en gel de polisacáridos ${ }^{2,3}$.

Se ha usado extensamente en cirugías de aumento del esqueleto facial. Es un material de uso fácil, resistente a la infección, biocompatible y clínicamente confiable en relación a la persistencia del efecto. Permite la osteoconducción y osteointegración. Puede ser visualizado mediante radiografía ${ }^{14}$.

Los gránulos de hidroxiapatita en gel han sido usados para aumentar la región glabelar, premaxilar, región de soporte del ala y dorso nasal, con buenos resultados, sin embargo no existen datos de seguimiento a largo plazo. Tiene el inconveniente de ser difícil de remover completamente ${ }^{2,14}$.

d) Polimetilmetacrilato (Metacrill ${ }^{\circledR}$ )

Polímero sintético en forma de microesferas de 30 a 40 um de diámetros, suspendidas en gel de colágeno. Una vez inyectado, el vehículo se absorbe y las microesferas son encapsuladas, siendo resistente a la degradación y fagocitosis. Ha sido usado con éxito en reemplazo articular, cirugía de cataratas, dental y neuroquirúrgica. En rinoplastía se ha usado en dorso, punta y premaxila. Posee un bajo riesgo de presentar reacciones adversas complejas como la formación de granulomas y rechazo, siendo difícil de remover ${ }^{1-3,15,16}$.

\section{DISCUSIÓN}

Los injertos autólogos siguen siendo la primera elección para la mayoría de los cirujanos. Su disponibilidad en el campo quirúrgico, los escasos problemas en el sitio donante, su alta integración y baja tasa de extrusión e infección en la gran mayoría de los pacientes juegan a su favor. Sin embargo, en ciertas circunstancias, tales como rinoplastía de revisión o malformaciones craneofaciales, pueden hacer difícil la obtención del injerto. Es en estos casos, donde escasean los injertos autólogos, en los que consideramos útil recurrir a materiales implantables. Otra situación en la que podría ser ventajoso su uso es en el paciente posoperado disconforme y que presenta imperfecciones menores. Aquí los materiales inyectables pudiesen ser una alternativa a la reoperación.

Finalmente, es importante tener en cuenta sus limitaciones y complicaciones, las que resumimos en la Tabla 1. No hay que olvidar que su reciente

Tabla 1. Ventajas y desventajas de aloplásticos

\begin{tabular}{|c|c|c|c|c|c|c|}
\hline & \multicolumn{3}{|c|}{ Ventajas } & \multicolumn{3}{|c|}{ Desventajas } \\
\hline & Soporte & Maleabilidad & Removilidad & Infección & $\begin{array}{l}\text { Rechazo/ } \\
\text { extrusión }\end{array}$ & Reabsorción \\
\hline \multicolumn{7}{|l|}{ Implantables } \\
\hline Silicona $\left(\right.$ Silastic $\left.{ }^{\circledR}\right)$ & ++ & - & ++ & t+ & +t+ & $-/+$ \\
\hline PAD (Medpore $\left.{ }^{\circledR}\right)$ & ++ & ++ & - & $-1+$ & ++ & $-/+$ \\
\hline Politetrafloruroetileno (Gore-Tex ${ }^{\circledR}$ ) & - & $+/-$ & + & $+/++$ & $-/+$ & $-/+$ \\
\hline \multicolumn{7}{|l|}{ Inyectables } \\
\hline Colágeno/Ac. hialurónico & - & - & - & - & + & +++ \\
\hline Hidroxiapatita & - & $-/+$ & - & - & - & - \\
\hline Polimetilmetacrilato & - & - & - & + & +++ & $-/+$ \\
\hline
\end{tabular}

(PAD: Polietileno de alta densidad). 
introducción y aprobación en plástica facial, nos obliga a ser cautelosos en su uso. Consideramos que son necesarios mayores estudios de largo plazo para poder zanjar esta discusión.

\section{BIBLIOGRAFÍA}

1. Sajuadian $A$, Rubinstein $R$, Naghshineh N. Current status of grafts and implants in rhinoplasty: part I. Autologous grafts. Plast Reconstr Surg 2010; 125(2): 40e-49e.

2. Sajuadian $A$, Naghshineh N, Rubinstein R. Current status of grafts and implants in rhinoplasty: Part II. Homologous grafts and allogenic implants. Plast Reconstr Surg 2010; 125(3): 99e-109e.

3. Berghaus A, Stelter K. Alloplastic materials in rhinoplasty. Curr Opin Otolaryngol Head Neck Surg 2006; 14(4): 270-7.

4. Brenner MJ, Hilger PA. Grafting in rhinoplasty. Facial Plast Surg Clin North Am 2009; 17(1): 91-113, vii.

5. Romo T, Kwak E. Nasal grafts and implants in revision rhinoplasty. Facial Plast Surg Clin North Am 2006; 14(4): 373-87, vii.

6. Wang JH, Lee BJ, Jang YJ. Use of silicone sheets for dorsal augmentation in rhinoplasty for Asian noses. Acta Otolaryngol Supp/ 2007; (558): 115-20.

7. Manavbasi I, Agaoglu G. Silicon template for nasal tip graft. Ann Plast Surg 2006; 56(2): 226.

8. Ahn J, Honrado C, Horn C. Combined silicone and cartilage implants: augmentation rhino- plasty in Asian patients. Arch Facial Plast Surg 2004; 6(2): 120-3.

9. Gürlek $A$, Celik M, Fariz $A$, Ersöz-Oztürk $A$, Eren AT, TENEKECI $G$. The use of high-density porous polyethylene as a custom-made nasal spreader graft. Anesthetic Plast Surg 2006; 30(1): 3441.

10. Mendelsohn M. Straightening the crooked middle third of the nose: using porous polyethylene extended spreader grafts. Arch Facial Plast Surg 2005; 7(2): 74-80.

11. Romo T, Litner J, Sclafani A. Management of the severe bulbous nasal tip using porous polyethylene alloimplants. Facial Plast Surg 2003; 19(4): 341-8.

12. Inanli $S$, Sari M, Baylancicek $S$. The use of expanded polytetrafluoroethylene (Gore-Tex) in rhinoplasty. Anesthetic Plast Surg 2007; 31(4): 345-8.

13. Jin HR, Lee JY, Yeon JY, Rhee CS. A multicenter evaluation of the safety of Gore-Tex as an implant in Asian rhinoplasty. Am J Rhinol 2006; 20(6):615-9.

14. Dayan SH, Greene RM, Chambers AA. Longlasting injectable implant for correcting cosmetic nasal deformities. Ear Nose Throat $J$ 2007; 86(1): 25-6.

15. Bagal A, Dahiya R, Tsai V, Adamson P. Clinical Experience With Polymethylmethacrylate Microspheres (Artecoll) for Soft-Tissue Augmentation. Arch Facial Plast Surg 2007; 9(4): 275-80.

16. Nácul A. Bioplastía Nasal. En: Nácul $A$, Bioplastía: la plástica interactiva. Sao Paulo: Amolca, 2009; 85-110. 